\title{
Management of atherosclerosis risk factors for patients at high cardiovascular risk in real-world practice: a multicentre study
}

\author{
Arintaya Phrommintikul ${ }^{1}$, MD, Rungroj Krittayaphong ${ }^{2}$, MD, Wanwarang Wongcharoen ${ }^{1}$, MD, Sukit Yamwong ${ }^{3}$, MD, \\ Smonporn Boonyaratavej ${ }^{4}$, MD, Rapeephon Kunjara-Na-Ayudhya ${ }^{5}$, MD, Pyatat Tatsanavivat ${ }^{6}$, MD, \\ Piyamitr Sritara $^{3}$, MD, CORE-Thailand investigators
}

INTRODUCTION Atherosclerotic cardiovascular disease is a global health burden. However, there are heterogeneities among countries or regions in the risk factors and clinical manifestations of atherosclerotic diseases as well as management patterns.

METHODS We collected data from 25 centres in Thailand. Patients with documented coronary artery disease, cerebrovascular disease or peripheral arterial disease, or with at least three atherosclerosis risk factors were enrolled between April 2011 and March 2014. Data on demographics, atherosclerosis risk factors and the management pattern of risk factors, including laboratory findings, were recorded.

RESULTS In total, 9,390 patients, including 4,861 patients with established atherosclerotic disease and 4,529 patients with multiple risk factors, were enrolled. The modifiable risk factors, other than current smoking habit (5.3\%), were common: hypertension (83.8\%), dyslipidaemia (85.9\%) and diabetes mellitus (57.4\%). A majority of patients with hypertension (96.3\%), dyslipidaemia (93.8\%) and diabetes mellitus (78.5\%) received medications for their conditions. Antiplatelet agents were given to $73.9 \%$ of patients. The undertreatment rate of cardiovascular risk factors, such as blood pressure, low-density lipoprotein cholesterol, haemoglobin A1c and smoking status, was $35.8 \%, 59.0 \%, 45.3 \%$ and $5.3 \%$, respectively. CONCLUSION Conventional atherosclerosis risk factors were common among Thai patients with established atherosclerotic disease. Even though most of the patients received recommended treatments according to established guidelines, a significant proportion of them were undertreated for atherosclerosis risk factors.

Keywords: atherosclerosis, risk factor, Thailand

\section{INTRODUCTION}

Atherosclerotic cardiovascular disease is a worldwide health problem associated with high morbidity, mortality and cost of care. As a result of advanced treatment, the death rate attributable to cardiovascular disease has declined in developed countries. However, the burden of disease remains high in both developed and developing countries ${ }^{(1,2)}$ due to the increased prevalence of atherosclerosis risk factors, such as hypertension and diabetes mellitus.(1) Furthermore, it has been shown that gaps between clinical practice guidelines and real-world practice lead to suboptimal risk factor control, ${ }^{(3-9)}$ contributing to higher rates of cardiovascular events. ${ }^{(8)}$ There are several factors involved in optimal risk factor control, including patients' clinical characteristics, ${ }^{(6,8-10)}$ ethnic variations in response to treatment, level of healthcare, ${ }^{(10)}$ cost of healthcare and physicians' compliance to guideline recommendations. ${ }^{(5)}$

Although the effects of modifiable, conventional atherothrombotic risk factors are well established, ${ }^{(11)}$ there are geographical variations related to its prevalence among various populations that may impact individual risk. ${ }^{(1)}$ For instance, the risk of death among Asians seems to be more strongly associated with low body mass index (BMI) than high BMI when compared to European populations. ${ }^{(11,12)}$ However, most randomised controlled trials (RCTs) on risk factor control and the benefits of cardiovascular event reduction have been conducted in Western patient populations. Genetic heterogeneity among patients of various ethnicities may also affect their response to treatment, such as the polymorphic cytochrome P450 (2C19) enzymes that are known to be associated with altered clopidogrel response. ${ }^{(13,14)}$ A recent meta-analysis has shown that Asians require a lower dosage of statins or lower intensity low-density lipoprotein cholesterol (LDL-C)-lowering therapy for coronary artery plaque regression when compared to Western patients. ${ }^{(15)}$

In addition to the differences in atherothrombotic risk and response to treatment, healthcare resources and physicians' attitudes toward the importance of atherosclerosis risk factors and the benefits of risk factor control could impact clinical practice and outcomes. Data from real-life practice can provide insights into the real-world prevalence of risk factors and risk factor control as well as their impact on long-term cardiovascular outcomes. This information would be useful for the development and implementation of local guidelines to improve quality of care

\footnotetext{
${ }^{1}$ Department of Internal Medicine, Faculty of Medicine, Chiang Mai University, Chiang Mai, ${ }^{2}$ Department of Medicine, Faculty of Medicine, Siriraj Hospital, ${ }^{3}$ Department of Medicine, Faculty of Medicine, Ramathibodi Hospital, Mahidol University, ${ }^{4}$ Department of Medicine, Faculty of Medicine, Chulalongkorn University, ${ }^{5}$ Vichaiyut Hospital and Medical Center, Bangkok, ${ }^{6}$ Department of Medicine, Faculty of Medicine, Khon Kaen University, Khon Kaen, Thailand

Correspondence: Prof Rungroj Krittayaphong, Consultant, Department of Medicine, Faculty of Medicine, Siriraj Hospital, Mahidol University, Bangkok 10700, Thailand. rungroj.kri@mahidol.ac.th
} 
and outcomes for patients with atherosclerotic cardiovascular diseases. Toward this end, a multicentre registry was established in Thailand to study, in real-world practice, the management pattern of atherosclerosis risk factors and the rate of undertreatment, reflecting nonadherence to standard recommendations in Thai patients at high risk of cardiovascular events.

\section{METHODS}

The Cohort Of patients with high Risk for cardiovascular Events (CORE-Thailand) registry is a prospective, multicentre, observational, longitudinal study of Thai patients with high atherosclerotic risk. The follow-up period was 60 months and is still ongoing. Baseline data was analysed for the purpose of this study. Investigators in the registry were internists, cardiologists, neurologists, endocrinologists, nephrologists and vascular surgeons. There were a total of 25 participating centres, including 13 university-affiliated hospitals, three teaching hospitals and nine secondary-care hospitals, representing varying levels of healthcare. These hospitals are located in different regions across Thailand. All patients received treatment according to the treatment plan devised by their primary physicians. The study was approved by the Joint Research Ethics Committee and Ministry of Public Health, Thailand. Informed consent was obtained from all patients prior to the commencement of the study.

Patients aged $\geq 45$ years with established coronary artery disease (CAD), cerebrovascular disease (CVD) or peripheral arterial disease (PAD), or with at least three atherosclerosis risk factors (i.e. multiple risk factors [MRFs]) were consecutively enrolled from the outpatient clinics from April 2011 to March 2014. Documented CAD consisted of one or more of the following criteria: stable angina with documented CAD; history of unstable angina with documented CAD; history of percutaneous coronary intervention; history of coronary artery bypass graft surgery; or previous myocardial infarction. Documented CVD consisted of hospitalisation following a diagnosis of transient ischaemic attack or ischaemic stroke. Documented PAD consisted of one or both of the following criteria: current intermittent claudication with ankle brachial index $<0.9$; and a previous history of surgery or intervention (such as angioplasty, stenting, peripheral arterial bypass graft or other vascular intervention, including amputation).

Risk factors consisted of those that were documented in the patients' medical records or those the patients were receiving treatment for at the time of enrolment in the study. They included: diabetes mellitus or impaired fasting glucose (IFG); hypertension (systolic blood pressure [SBP] $\geq 140 \mathrm{mmHg}$ and/or diastolic blood pressure $[\mathrm{DBP}] \geq 90 \mathrm{mmHg}$, or currently being treated with antihypertensive agents); dyslipidaemia that could involve hypercholesterolaemia (total cholesterol $>200 \mathrm{mg} / \mathrm{dL}$ or LDL-C $>130 \mathrm{mg} / \mathrm{dL}$ ), hypertriglyceridaemia (triglyceride $>150 \mathrm{mg} / \mathrm{dL}$ ) or low high-density lipoprotein cholesterol (HDL-C $<40 \mathrm{mg} / \mathrm{dL}$ ), or current treatment with lipid-modifying agents; chronic kidney disease (proteinuria or estimated glomerular filtration rate $<60 \mathrm{~mL} / \mathrm{min}$ ); current smoking habit of at least one cigarette per day; men aged $\geq 55$ years or women aged $\geq 65$ years; and family history of premature atherosclerosis. Patients who met the following criteria were excluded from the study: an acute atherosclerotic event within the past three months; a large aortic aneurysm indicated for surgery; previous participation in a blinded clinical trial; limited life expectancy due to noncardiovascular conditions (such as cancer or documented HIV infection); or possible difficulty returning for follow-up visits.

Patients were evaluated at baseline for demographic and medical characteristics, and scheduled for re-evaluation at six, 12, 24, 36, 48 and 60 months. Patient data collected were height, weight, waist circumference, seated SBP and DBP, ankle brachial index, available laboratory data and medications. Clinical data and cardiovascular events were to be prospectively determined. Data was collected locally using a standardised case report form and forwarded to the data management group at MedResNet (Medical Research Network of the Consortium of Thai Medical Schools), Thailand. The data management group and statistician performed quality data checks prior to data analysis. The annual site monitoring was performed randomly. Risk factor control was evaluated for patients with available data according to current recommendations. ${ }^{(16-18)}$ Patients with controlled risk factors were defined as those with SBP $<140 \mathrm{mmHg}$ or DBP $<90 \mathrm{mmHg}$; LDL-C $<70 \mathrm{mg} / \mathrm{dL}$ for patients with established atherosclerotic disease (EAD) or LDL-C $<100 \mathrm{mg} / \mathrm{dL}$ for patients with MRFs; and haemoglobin A1c $(\mathrm{HbA} 1 \mathrm{c})<7 \%$.

Continuous variables were expressed as mean \pm standard deviation and compared between patient groups using Student's $t$-test or one-way analysis of variance, where appropriate. Categorical variables were expressed as frequencies and percentages and compared between groups using Pearson's chisquare test. Statistical significance was considered as a two-tailed probability of $\mathrm{p}<0.05$. Statistical analysis was performed using IBM SPSS Statistics version 19.0 (IBM Corp, Armonk, NY, USA).

\section{RESULTS}

Among 9,390 enrolled patients, 4,861 patients had EAD and 4,529 patients had MRFs. Among EAD patients, CAD, CVD, PAD and polyvascular ( $>1$ vascular bed) disease presented in 3,804 (78.3\%), 572 (11.8\%), 154 (3.2\%) and 331 (6.8\%) patients, respectively (Fig. 1). The profile and clinical characteristics of our study population are given in Fig. 1 and Table I, respectively.

The mean age of our patient population was $65.6 \pm 9.7$ years and patients with PAD were significantly older than the others (PAD $69.0 \pm 10.9$ years, CAD $65.4 \pm 9.6$ years, CVD $65.1 \pm$ 9.9 years, MRFs $65.6 \pm 9.6$ years; $p<0.01$ for all comparisons between PAD and other patient groups). Approximately half $(54.8 \%)$ of the population were men and there were more male patients with EAD than with MRFs $(65.7 \%$ vs. $43.0 \%$; $p<0.001)$. Conventional cardiovascular risk factors were common among patients with established disease. Overall, diabetes mellitus or IFG, hypertension and dyslipidaemia presented in $57.4 \%$, $83.8 \%$ and $85.9 \%$ of patients, respectively. The prevalence of a current smoking habit among patients with established disease was $6.4 \%$ and was highest among patients with PAD (13.6\%; $p<0.01$ compared to all other groups). Among patients with MRFs, the most common atherosclerosis risk factors were 
Table I. Clinical characteristics of patients.

\begin{tabular}{|c|c|c|c|c|}
\hline \multirow[t]{2}{*}{ Variable } & \multicolumn{3}{|c|}{ No. (\%) } & \multirow[t]{2}{*}{ p-value } \\
\hline & $\begin{array}{c}\text { Total } \\
(n=9,390)\end{array}$ & $\begin{array}{l}\text { Patients with EAD } \\
\text { ( }(n=4,861)\end{array}$ & $\begin{array}{l}\text { Patients with MRFs } \\
\qquad(n=4,529)\end{array}$ & \\
\hline Male gender & $5,144(54.8)$ & $3,195(65.7)$ & $1,949(43.0)$ & $<0.001$ \\
\hline Men aged $\geq 55 \mathrm{yr} /$ women aged $\geq 65 \mathrm{yr}$ & $6,925(73.7 \%)$ & $3,726(76.7)$ & $3,199(70.6)$ & $<0.001$ \\
\hline Diabetes mellitus/IFG & $5,394(57.4)$ & $2,017(41.5)$ & $3,377(74.6)$ & $<0.001$ \\
\hline Hypertension & $7,867(83.8)$ & $3,624(74.6)$ & $4,243(93.7)$ & $<0.001$ \\
\hline Dyslipidaemia & $8,066(85.9)$ & $3,840(79.0)$ & $4,226(93.3)$ & $<0.001$ \\
\hline Current smoking habit & $497(5.3)$ & $311(6.4)$ & $186(4.1)$ & $<0.001$ \\
\hline Family history of premature atherothrombosis & $736(7.8)$ & $407(8.4)$ & $329(7.3)$ & 0.046 \\
\hline Waist circumference $(\mathrm{cm})^{*}$ & $88.5 \pm 11.4$ & $87.4 \pm 11.6$ & $89.6 \pm 11.2$ & $<0.001$ \\
\hline BMI $\left(\mathrm{kg} / \mathrm{m}^{2}\right)^{*,+}$ & $\begin{array}{l}25.4 \pm 6.5 \\
(n=9,169)\end{array}$ & $\begin{array}{l}24.8 \pm 7.8 \\
(n=4,707)\end{array}$ & $\begin{array}{l}26.1 \pm 4.6 \\
(n=4,462)\end{array}$ & $<0.001^{*}$ \\
\hline Underweight/normal & $2,693(29.4)$ & $1,612(34.2)$ & $1,081(24.2)$ & \\
\hline Overweight & $1,934(21.1)$ & $1,039(22.1)$ & $895(20.1)$ & \\
\hline Obesity Class I & $3,340(36.4)$ & $1,603(34.1)$ & $1,737(38.9)$ & \\
\hline Obesity Class II & $959(10.5)$ & $379(8.1)$ & $580(13.0)$ & \\
\hline Obesity Class III & $243(2.7)$ & $74(1.6)$ & $169(3.8)$ & \\
\hline
\end{tabular}

*Data presented as mean \pm standard deviation. +Underweight $/$ normal $<23.0 \mathrm{~kg} / \mathrm{m}^{2}$, Overweight $23.0-24.9 \mathrm{~kg} / \mathrm{m}^{2}$, Obesity Class I $25.0-29.9 \mathrm{~kg} / \mathrm{m}^{2}$, Obesity Class II $30.0-34.9 \mathrm{~kg} / \mathrm{m}^{2}$, Obesity Class III $\geq 35.0 \mathrm{~kg} / \mathrm{m}^{2}$. $\neq \mathrm{p}<0.001$ for both comparison of mean BMI and categorical comparison of BMI. BMI: body mass index; EAD: established atherosclerotic disease; IFG: impaired fasting glucose; MRFs: multiple risk factors

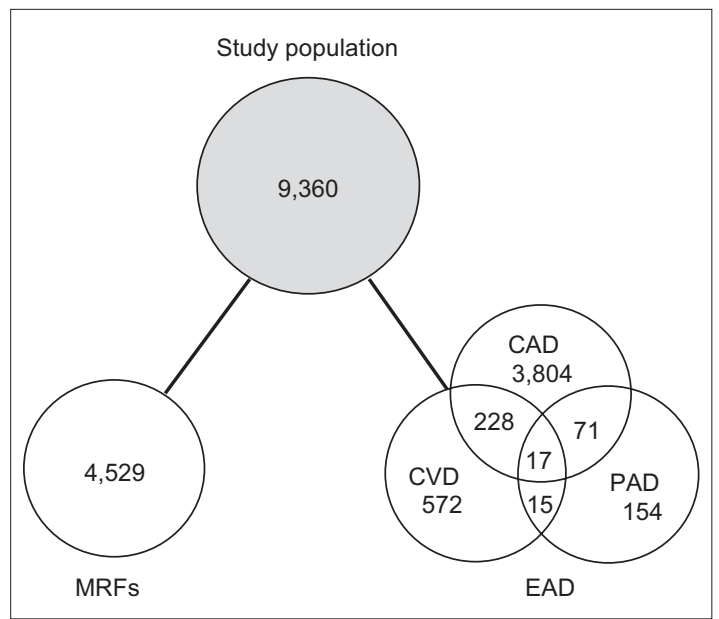

Fig. 1 Diagram shows the profile of the study population. CAD: coronary artery disease; CVD: cerebrovascular disease; EAD: established atherosclerotic diseases; MRFs: multiple risk factors; PAD: peripheral arterial disease

hypertension (93.7\%) and dyslipidaemia (93.3\%). Baseline BMI data was available for 9,169 (97.6\%) patients. The prevalence of overweight and obesity $(21.1 \%$ and $49.5 \%$, respectively) was high among both patients with EAD and MRFs (Table I).

The risk factor assessment of patients at the time of enrolment is shown in Table II. Baseline SBP and DBP among patients with MRFs were $134.8 \pm 17.1 \mathrm{mmHg}$ and $75.3 \pm 10.8 \mathrm{mmHg}$, respectively. Among 1,523 patients without diagnosed hypertension, baseline blood pressure was elevated (SBP $\geq 140 \mathrm{mmHg}$ and/or DBP $\geq 90 \mathrm{mmHg}$ ) for 283 (18.6\%) patients. Overall mean fasting blood sugar (FBS) and $\mathrm{HbA} 1 \mathrm{c}$ were 127.4 $\pm 49.5 \mathrm{mg} / \mathrm{dL}$ and $7.2 \% \pm 1.6 \%$, respectively, among patients for whom laboratory data was available. Among patients for whom laboratory data was available, and who had no history of diabetes mellitus or IFG and did not receive hypoglycaemia agents, elevated FBS ( $\geq 110 \mathrm{mg} / \mathrm{dL}$ ) and $\mathrm{HbA} 1 \mathrm{c}(\geq 6.5 \%)$ presented in $18.3 \%(351 / 1,918)$ and $13.2 \%(59 / 448)$ of patients, respectively. From available lipid profiles, the overall mean LDL-C, HDL-C and TG levels were $93.4 \pm 35.2 \mathrm{mg} / \mathrm{dL}, 49.7 \pm 14.6 \mathrm{mg} / \mathrm{dL}$ and $140.9 \pm 91.2 \mathrm{mg} / \mathrm{dL}$, respectively.

The medications used for each patient group are summarised in Table III. Antiplatelet agents were used for 4,695 (96.6\%) patients with EAD, ranging from $82.5 \%, 91.4 \%, 96.1 \%$ and $98.0 \%$ in patients with PAD, CVD, polyvascular disease and CAD, respectively $(p<0.001)$. Among patients with MRFs, $2,245(49.6 \%)$ patients received antiplatelet agents as primary prevention. Aspirin was the most common antiplatelet agent used. Statins were used for 4,449 (91.5\%) patients with EAD and ranged from $63.6 \%, 80.4 \%, 90.9 \%$ and $94.3 \%$ in PAD, CVD, polyvascular disease and CAD, respectively $(p<0.001)$. Among patients with MRFs, 3,794 (83.8\%) patients received statins.

Among 7,867 patients with hypertension or elevated blood pressure, antihypertensive agents were prescribed for $7,576(96.3 \%)$ patients, ranging from $85(77.3 \%), 409$ (89.3\%), $269(94.4 \%), 4,070(95.9 \%)$ and 2,743 (99.0\%) in patients with PAD, CVD, polyvascular disease, MRF and CAD, respectively $(p<0.001)$. Among 5,394 patients with diabetes mellitus or elevated FBS, antidiabetic agents were prescribed in 4,236 (78.5\%) patients, which included 21 (40.4\%), 167 (68.2\%), 108 (68.8\%), $1184(75.8 \%)$ and $2756(81.6 \%)$ in patients with PAD, CVD, polyvascular disease, CVD and MRF, respectively $(p<0.001)$.

The rate of undertreatment of atherosclerosis risk factors for the three modifiable risk factors (defined as: $\mathrm{SBP}>140 \mathrm{mmHg}$ or DBP > $90 \mathrm{mmHg}$; LDL-C > $70 \mathrm{mg} / \mathrm{dL}$ in patients with EAD 
Table II. Risk factor assessment at enrolment.

\begin{tabular}{|c|c|c|c|c|}
\hline \multirow[t]{2}{*}{ Variable } & \multicolumn{3}{|c|}{ Mean \pm standard deviation } & \multirow[t]{2}{*}{ p-value } \\
\hline & $\begin{array}{c}\text { Total } \\
(n=9,390)\end{array}$ & $\begin{array}{l}\text { Patients with } \\
\text { EAD }(n=4,861)\end{array}$ & $\begin{array}{c}\text { Patients with } \\
\text { MRFs (n=4,529) }\end{array}$ & \\
\hline $\operatorname{DBP}(\mathrm{mmHg})(\mathrm{n}=9,384)$ & $74.6 \pm 11.1$ & $73.9 \pm 11.3$ & $75.3 \pm 10.8$ & $<0.001$ \\
\hline $\mathrm{TC}(\mathrm{mg} / \mathrm{dL})(\mathrm{n}=5,300)$ & $170.0 \pm 40.3$ & $164.8 \pm 40.0$ & $174.5 \pm 40.0$ & $<0.001$ \\
\hline LDL-C (mg/dL) $(n=5,762)$ & $93.4 \pm 35.2$ & $93.3 \pm 33.3$ & $99.4 \pm 34.1$ & 0.003 \\
\hline HDL-C $(m g / d L)(n=5,233)$ & $49.7 \pm 14.6$ & $46.5 \pm 13.9$ & $52.5 \pm 14.7$ & $<0.001$ \\
\hline $\mathrm{TG}(\mathrm{mg} / \mathrm{dL})(\mathrm{n}=5,435)$ & $140.9 \pm 91.2$ & $143.0 \pm 94.2$ & $139.1 \pm 88.5$ & 0.116 \\
\hline HbA1c $(\%)(n=3,677)$ & $7.2 \pm 1.6$ & $7.2 \pm 1.6$ & $7.2 \pm 1.5$ & 0.879 \\
\hline
\end{tabular}

DBP: diastolic blood pressure; EAD: established atherosclerotic disease; HbA1c: haemoglobin A1c; HDL-C: high-density lipoprotein cholesterol; LDL-C: low-density lipoprotein cholesterol; MRFs: multiple risk factors; SBP: systolic blood pressure; TC: total cholesterol; TG: triglyceride

Table III. Medications used in each population.

\begin{tabular}{|c|c|c|c|c|}
\hline \multirow[t]{2}{*}{ Variable } & \multicolumn{3}{|c|}{ No. (\%) } & \multirow[t]{2}{*}{ p-value } \\
\hline & $\begin{array}{c}\text { Total } \\
(n=9,390)\end{array}$ & $\begin{array}{c}\text { Patients with } \\
\text { EAD }(n=4,861)\end{array}$ & $\begin{array}{c}\text { Patients with } \\
\text { MRFs }(n=4,529)\end{array}$ & \\
\hline Antihypertensive agents & $7,576(96.3)$ & $3,506(96.7)$ & $4,070(95.9)$ & $<0.006$ \\
\hline ACEI & $2,673(34.0)$ & $1,340(37.0)$ & $1,333(31.4)$ & $<0.001$ \\
\hline CCB & $3,660(46.5)$ & 1,362 (37.6) & $2,298(54.2)$ & $<0.001$ \\
\hline Diuretics & $2,363(30.0)$ & $987(27.2)$ & $1,376(32.4)$ & $<0.001$ \\
\hline Beta blocker & $4,234(53.8)$ & $2,694(74.3)$ & $1,540(36.3)$ & $<0.001$ \\
\hline Patients with DM or elevated FBS/HbA1c & $5,394(57.4)$ & $2,017(41.5)$ & $3,377(74.6)$ & $<0.001$ \\
\hline Antidiabetic agents & $4,236(78.5)$ & $1,480(73.4)$ & $2,756(81.6)$ & $<0.001$ \\
\hline Metformin & $3,119(57.8)$ & $1,028(51.0)$ & $2,091(61.9)$ & $<0.001$ \\
\hline Thiazolidinedione & $687(12.7)$ & $149(7.4)$ & $538(15.9)$ & $<0.001$ \\
\hline DPP4 inhibitors & $382(7.1)$ & $125(6.2)$ & $257(7.6)$ & 0.036 \\
\hline Insulin & 965 (17.9) & $287(14.2)$ & $678(20.1)$ & $<0.001$ \\
\hline Patients with dyslipidaemia & $8,066(85.9)$ & $3,840(79.0)$ & $4,226(93.3)$ & $<0.001$ \\
\hline Lipid management agents & $7,569(93.8)$ & $3,659(95.3)$ & $3,910(92.5)$ & $<0.001$ \\
\hline Fibrate & $689(8.5)$ & $256(6.7)$ & $433(10.2)$ & $<0.001$ \\
\hline Statin & $7,281(90.3)$ & $3,587(93.4)$ & $3,694(87.4)$ & $<0.001$ \\
\hline Patients requiring statin (with \& without dyslipidaemia) & $8,243(87.8)$ & $4,449(91.5)$ & $3,794(83.8)$ & $<0.001$ \\
\hline Patients requiring antiplatelet agent & $6,940(73.9)$ & $4,695(96.6)$ & $2,245(49.6)$ & $<0.001$ \\
\hline Aspirin (all) & $6,263(66.7)$ & $4,225(86.9)$ & $2,038(45.0)$ & $<0.001$ \\
\hline Clopidogrel (all) & $2,065(22.0)$ & $1,925(39.6)$ & $140(3.1)$ & $<0.001$ \\
\hline
\end{tabular}

ACEI: angiotensin-converting enzyme inhibitor; ARB: angiotensin receptor blocker; BP: blood pressure; CCB: calcium channel blocker; DM: diabetes mellitus; DPP4: dipeptidyl peptidase 4; EAD: established atherosclerotic disease; FBS: fasting blood sugar; HbA1c: haemoglobin A1c; MRFs: multiple risk factors

or LDL-C $<100 \mathrm{mg} / \mathrm{dL}$ in those with MRFs; and HbA1c > 7\%) remained high (Fig. 2). Overall, the rate of undertreatment among our patients was $35.8 \%, 59.0 \%$ and $45.3 \%$ for blood pressure, LDL-C and HbA1c, respectively. When compared to those with MRFs, the rate of undertreatment of patients with EAD was lower for blood pressure, higher for LDL-C and comparable for HbA1c. The higher rate of undertreatment of LDL-C among patients with EAD may be related to lower targets of LDL-C levels in this patient group when compared to patients with MRFs. The overall rate of a current smoking habit was $5.3 \%$ among our patients, and was higher among patients with EAD. The rate of undertreatment of cardiovascular risk factors was not different among the patient groups with EAD (Fig. 3).

\section{DISCUSSION}

The CORE-Thailand registry provides real-world data on patients with EAD or MRFs in Thailand. This study, which presented the baseline characteristics of this population, showed the high prevalence of conventional atherosclerosis risk factors among patients with EAD. The medical therapies for risk factor control 


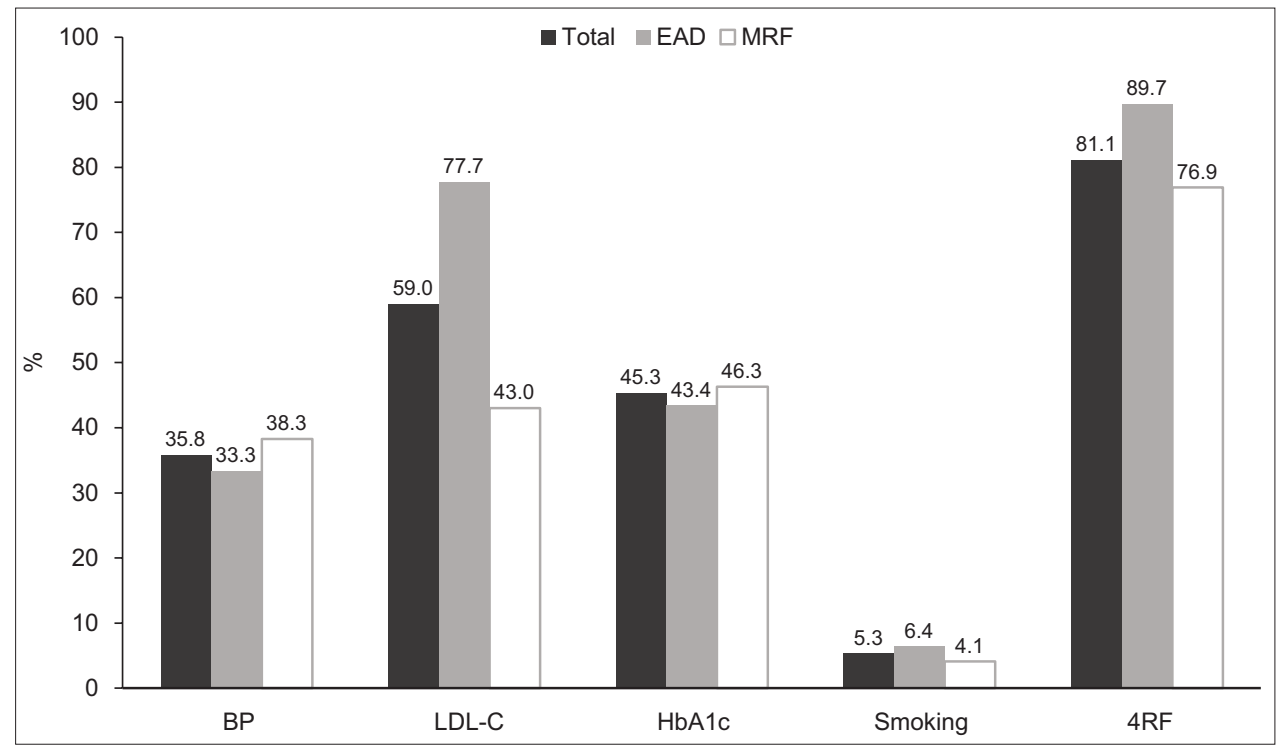

Fig. 2 Chart shows the rate of undertreatment of each of the cardiovascular risk factors in patients with established atherosclerotic disease (EAD) or multiple risk factors (MRFs). 4RF: all 4 risk factors; BP: blood pressure; HbA1c: haemoglobin A1c; LDL-C: low-density lipoprotein cholesterol

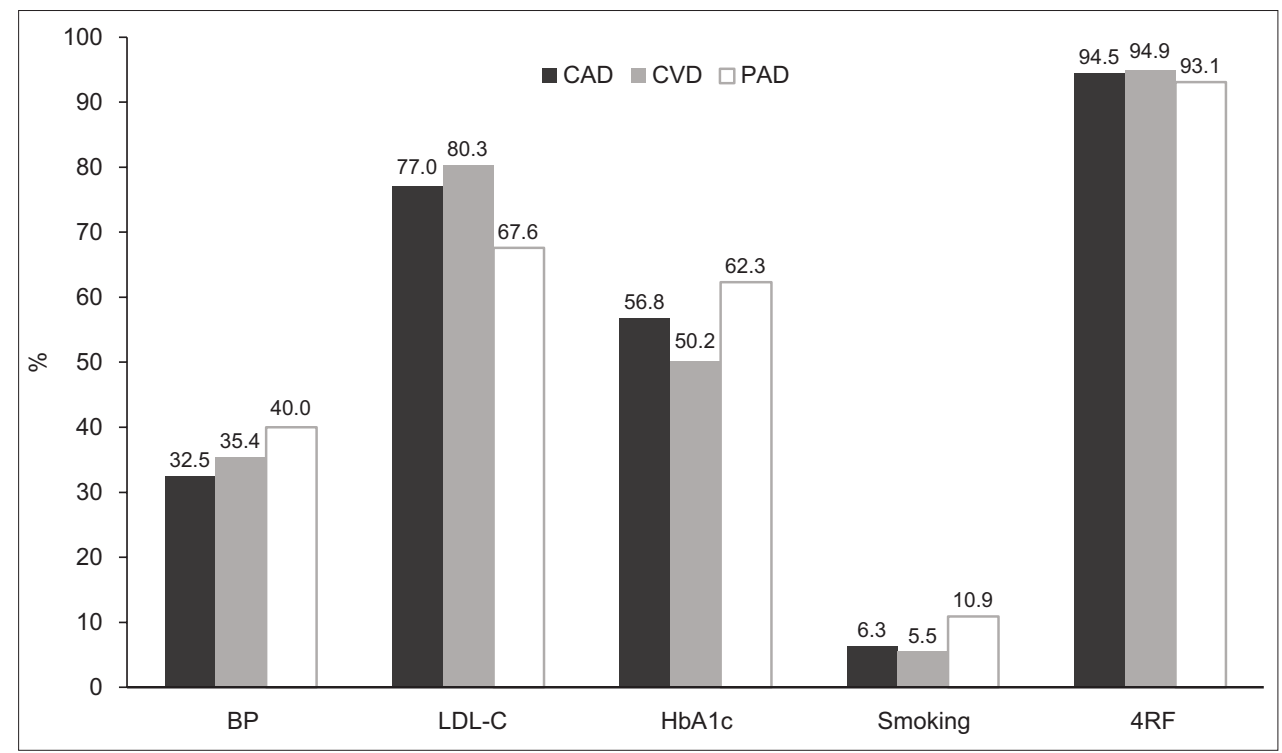

Fig. 3 Chart shows the rate of undertreatment of each of the cardiovascular risk factors among patients with various established atherosclerotic diseases. 4RF: all 4 risk factors; BP: blood pressure; CAD: coronary artery disease; CVD: cerebrovascular disease; HbA1c: haemoglobin A1c; LDL-C: low-density lipoprotein cholesterol; PAD: peripheral arterial disease

in our population were harmonised with established clinical practice guidelines, but the rate of risk factor control was low. Nevertheless, compared to previous cohorts of patients with atherothrombotic cardiovascular disease, ${ }^{(3,8)}$ our findings are more relevant vis-à-vis current guidelines and recommendations.

Among patients with EAD, conventional risk factors, including hypertension, diabetes mellitus and dyslipidaemia, were prevalent and comparable to those among the patient populations in the REACH registry, which had a prevalence of $80.0 \%, 37.5 \%$ and $70.2 \%$ for hypertension, diabetes mellitus and dyslipidaemia, respectively. ${ }^{(19)}$ While the prevalence of obesity $\left(\mathrm{BMI}>25 \mathrm{~kg} / \mathrm{m}^{2}\right)$ in our cohort was lower than that of the overall population (49.5\% vs. $68.3 \%$ ), it was comparable to findings for Asian populations in the REACH registry $(42.4 \%) .{ }^{(19)}$ Although Thailand has promulgated antismoking campaigns over the past
20 years, smoking is still the common modifiable risk factor in the country. ${ }^{(20)}$ Nevertheless, the prevalence of a current smoking habit among our patients with EAD and MRFs was lower than in previous registries; for instance, the prevalence of smoking in acute coronary syndrome patients was about 30\%. ${ }^{(21-23)}$ Attempting smoking cessation in patients with EAD or MRF may achieve a higher success rate than in patients who are unaware of disease or risk factors.

With respect to risk factor control, enrolled patients had no acute atherosclerotic event for at least three months, which is the period during which risk factors would be optimally controlled. The proportion of patients receiving the recommended therapy for risk factor control, including statin, antihypertensive agents and hypoglycaemic agents, was high, and comparable or greater than in previous registries. ${ }^{(3,19)}$ Statin, antihypertensive agents 
and hypoglycaemic agents were prescribed in 69.4\%, 95.8\% and $85.9 \%$ of patients in the $\mathrm{REACH}$ registry. However, the target achievement of each individual risk factor or the overall risk factors was still low. Similar to other cohorts, only a small proportion of patients achieved the target of risk factor control in our study $(18.9 \%$ vs. $16 \%-21 \%$ in our cohort vs. REACH registry for achieving four major risk factors) and patients with PAD had the highest rate of undertreatment of risk factors when compared to other patient groups. ${ }^{(8)}$

Hypercholesterolaemia and hypertension were the most common risk factors, as well as the most common suboptimally controlled risk factors. The benefits of $L D L-C$ reduction have been emphasised by several RCTs. ${ }^{(18)}$ Retrospective cohort studies in Thailand have also shown the benefits of LDL-C goal attainment for the reduction of first and recurrent cardiovascular events following acute coronary syndrome. ${ }^{(24,25)}$ Although the guidelines recommend a goal of LDL-C $<70 \mathrm{mg} / \mathrm{dL}$ for patients with EAD, LDL-C goal attainment rates remain low worldwide and have been reported to be in the range of $17 \%-35 \%$. $^{(3-5,26-29)}$ Some studies ${ }^{(3,8,26)}$ that were conducted when the recommended guideline was based on the 2004 updated National Cholesterol Education Program III ${ }^{(30)}$ have suggested setting LDL-C goals of $100 \mathrm{mg} / \mathrm{dL}$ before considering the use of a non-statin drug, such as ezetimibe. Similar to these other studies, ${ }^{(3,8,26)}$ our patients with EAD had a high undertreatment rate in terms of LDL-C reduction even though most patients received statins. In patients with MRFs, nearly $90 \%$ of them received statin as the primary prevention measure. However, the mean LDL-C in these patients was not different from that in patients with EAD. Due to the higher LDL-C goal, the rate of undertreatment in terms of LDL-C reduction in patients with MRFs was lower than the rate in patients with EAD. A meta-analysis of patients with lower cardiovascular risk has shown the benefits of LDL-C reduction using statins for cardiovascular events, albeit to a smaller magnitude. ${ }^{(31)}$ The benefits of statins for atherothrombotic event reduction still remain even after taking into consideration the risk of statin-associated adverse events, such as myopathy, new-onset diabetes mellitus or increased haemorrhagic stroke. ${ }^{(31)}$ However, the benefits of statin for primary prevention in real-life practice should be studied, especially among Asian patients who have a higher incidence of haemorrhagic stroke. ${ }^{(32-34)}$

It is worth noting that in the past decade, several studies have looked at the associations between LDL-C, statin potency and cardiovascular events, leading to the lowering of LDL-C goals, as reflected in the current updated recommendations. In addition, during the enrollment of the CORE-Thailand registry, the 2013 ACC/AHA (American College of Cardiology/American Heart Association) Guideline on the Treatment of Blood Cholesterol to Reduce Atherosclerotic Cardiovascular Risk in Adults was published, and recommended statin potency based on patient risk rather than LDL-C goal attainment. ${ }^{(35)}$ The discrepancies between guidelines may affect physicians' practice and LDL-C levels. The effects of having varying recommendations from different guidelines and the availability of generic statins at different periods of time for LDL-C goal attainment will be studied during the follow-up visits of the CORE-Thailand registry.

In contrast to LDL-C, the benefits of tight control of blood pressure and blood sugar appear less convincing for patients with established cardiovascular disease. ${ }^{(36,37)}$ Recent guidelines do not recommend tight control and have raised the target blood pressure and HbA1c levels. ${ }^{(17,38)}$ However, only two-thirds of our study population for whom data was available achieved the suggested targets for blood pressure and glycaemic control.

Further study of the factors associated with the high undertreatment rate in our cohort is warranted to improve the standard of care in clinical practice. Several potential factors may contribute to suboptimal risk factor control, including physicians' discretion to use low-potency medications as the first-line treatment, ${ }^{(5,39)}$ their inertia to adjust treatment plans, ${ }^{(26)}$ drug accessibility, the adverse effects of medications ${ }^{(27)}$ and patients' adherence to treatment regimens. Another factor related to physicians may be adherence to older guidelines, while in patients, the fear of adverse effects from medication and lack of knowledge about the results of undertreatment may lead to poor compliance to treatment plans. In addition to pharmacological management, lifestyle modifications, such as exercise and diet, have been shown to improve atherosclerosis risk factors and cardiovascular outcomes. ${ }^{(40,41)}$ However, the benefits of lifestyle modifications may receive less consideration than pharmacological therapy, leading to limited recommendations by healthcare personnel and low adherence from patients. Hence, the high undertreatment rate may be due to both patient and physician factors, and the possibility of poor compliance should be explored before concluding that the treatment provided to the patient may have been inadequate. Given the multiplicity of potential factors that could contribute to suboptimal risk factor control, the reasons behind the high undertreatment rate seen among patients with EAD warrant further study.

Although the benefits of aspirin for secondary prevention are well established, its benefit for primary prevention is inconclusive, leading to discrepancies among various guidelines. ${ }^{(38,42,43)} \mathrm{A}$ metaanalysis of aspirin for the primary and secondary prevention of vascular diseases showed benefits with respect to a small reduction in vascular events, but elevated risk of major bleeding, leading to an uncertain net value. ${ }^{(4)}$ Recent RCTs did not show benefits from aspirin for primary prevention among elderly Japanese patients with atherosclerosis risk factors. ${ }^{(45)}$ Of note, the inclusion criteria of the earlier study was the presence of at least one atherosclerosis risk factor, resulting in low rates of cardiovascular events during a five-year follow-up. In contrast, our cohort enrolled patients with more atherosclerosis risk factors, and therefore the effects noted for aspirin may be different.

The present study had several strengths. It had a large, ongoing cohort of patients with atherosclerotic disease who were enrolled from various secondary and tertiary healthcare hospitals in Southeast Asia. The study is therefore representative of the reallife clinical practice seen in different healthcare schemes that is likely to affect treatment strategy and outcomes. However, there were some limitations as well. Due to the limited number of patients with CVD and PAD in our study, our findings may not be 
generalisable to these patient populations. Although our cohort involved various healthcare levels and schemes, primary care physicians were not involved in the study. This notwithstanding, the effects of risk factor control on patients' cardiovascular outcomes during the ongoing follow-up of our cohort should remain relevant for all levels of healthcare.

In conclusion, conventional atherosclerosis risk factors were common among patients with EAD in the CORE-Thailand registry. Even though most patients received treatment as recommended by current established guidelines, suboptimal risk factor control was seen for most patients. The follow-up phase of this registry will provide better insight into the actual impact of suboptimal risk factor control on cardiovascular outcomes in our Asian population.

\section{ACKNOWLEDGEMENTS}

This study was supported by the Heart Association of Thailand under the Royal Patronage of H.M. the King, the National Research Council of Thailand, Sanofi-Aventis Thailand and AstraZeneca Thailand. We would like to thank the cohort coordinator, Siriluck Gunaparn. We also acknowledge the contribution of the many investigators and research assistants associated with this study.

\section{REFERENCES}

1. Go AS, Mozaffarian D, Roger VL, et al; American Heart Association Statistics Committee and Stroke Statistics Subcommitte. Heart disease and stroke statistics--2014 update: a report from the American Heart Association. Circulation 2014; 129:e28-e292.

2. Porapakkham Y, Rao C, Pattaraarchachai J, et al. Estimated causes of death in Thailand, 2005: implications for health policy. Popul Health Metr 2010; 8:14.

3. Park JE, Chiang CE, Munawar M, et al. Lipid-lowering treatment in hypercholesterolaemic patients: the CEPHEUS Pan-Asian survey. Eur J Prev Cardiol 2012; 19:781-94.

4. Sukonthasarn A, Homsanit M, Prommete B, et al. Lipid-lowering treatment in hypercholesterolemic patients: the CEPHEUS Thailand survey. J Med Assoc Thai 2011; 94:1424-34.

5. Karalis DG, Victor B, Ahedor L, Liu L. Use of lipid-lowering medications and the likelihood of achieving optimal LDL-cholesterol goals in coronary artery disease patients. Cholesterol 2012; 2012:861924.

6. Cheng EM, Asch SM, Brook RH, et al. Suboptimal control of atherosclerotic disease risk factors after cardiac and cerebrovascular procedures. Stroke 2007; 38:929-34.

7. Tully L, Gianos E, Vani A, et al. Suboptimal risk factor control in patients undergoing elective coronary or peripheral percutaneous intervention. Am Heart J 2014; 168:310-6.e3.

8. Cacoub PP, Abola MT, Baumgartner I, et al; REACH Registry Investigators. Cardiovascular risk factor control and outcomes in peripheral artery disease patients in the Reduction of Atherothrombosis for Continued Health (REACH) Registry. Atherosclerosis 2009; 204:e86-92.

9. Steg PG, Bhatt DL, Wilson PW, et al; REACH Registry Investigators. One-year cardiovascular event rates in outpatients with atherothrombosis. JAMA 2007; 297:1197-206.

10. Driscoll A, Beauchamp A, Lyubomirsky G, et al. Suboptimal management of cardiovascular risk factors in coronary heart disease patients in primary care occurs particularly in women. Intern Med J 2011; 41:730-6.

11. Yusuf S, Hawken S, Ounpuu S, et al; INTERHEART Study Investigators. Effect of potentially modifiable risk factors associated with myocardial infarction in 52 countries (the INTERHEART study): case-control study. Lancet 2004; 364:937-52

12. Zheng W, McLerran DF, Rolland B, et al. Association between body-mass index and risk of death in more than 1 million Asians. N Engl J Med 2011; 364:719-29.

13. Zou J, Xie HG, Chen SL, et al. Influence of CYP2C19 loss-of-function variants on the antiplatelet effects and cardiovascular events in clopidogrel-treated Chinese patients undergoing percutaneous coronary intervention. Eur J Clin Pharmacol 2013; 69:771-7.

14. Jia DM, Chen ZB, Zhang MJ, et al. CYP2C19 polymorphisms and antiplatelet effects of clopidogrel in acute ischemic stroke in China. Stroke 2013; 44:171 7-9.

15. Li YF, Feng QZ, Gao WQ, et al. The difference between Asian and Western in the effect of LDL-C lowering therapy on coronary atherosclerotic plaque: a meta-analysis report. BMC Cardiovasc Disord 2015; 15:6.

16. Rydén L, Grant PJ, Anker SD, et al. ESC Guidelines on diabetes, pre-diabetes, and cardiovascular diseases developed in collaboration with the EASD: the Task Force on diabetes, pre-diabetes, and cardiovascular diseases of the European Society of Cardiology (ESC) and developed in collaboration with the European Association for the Study of Diabetes (EASD). Eur Heart J 2013; 34:3035-87.

17. Mancia G, Fagard R, Narkiewicz K, R, et al. 2013 ESH/ESC guidelines for the management of arterial hypertension: the task force for the management of arterial hypertension of the European Society of Hypertension (ESH) and of the European Society of Cardiology (ESC). Eur Heart J 2013; 34:2159-219.

18. European Association for Cardiovascular Prevention \& Rehabilitation, Reiner Z, Catapano AL, et al; ESC Committee for Practice Guidelines (CPG) 2008-2010 and 2010-2012 Committees. ESC/EAS Guidelines for the management of dyslipidaemias: the Task Force for the management of dyslipidaemias of the European Society of Cardiology (ESC) and the European Atherosclerosis Society (EAS). Eur Heart J 2011; 32:1769-818.

19. Bhatt DL, Steg PG, Ohman EM, et al; REACH Registry Investigators. International prevalence, recognition, and treatment of cardiovascular risk factors in outpatients with atherothrombosis. JAMA 2006; 295:180-9

20. Vathesatogkit $P$, Charoenca N. Tobacco control: lessons learnt in Thailand. Indian J Public Health 2011; 55:228-33.

21. Himbert D, Klutman M, Steg G, White K, Gulba DC; GRACE Investigators. Cigarette smoking and acute coronary syndromes: a multinational observational study. Int J Cardiol 2005; 100:109-17.

22. Nakamura K, Barzi F, Lam TH, et al; Asia Pacific Cohort Studies Collaboration. Cigarette smoking, systolic blood pressure, and cardiovascular diseases in the Asia-Pacific region. Stroke 2008; 39:1694-702.

23. Srimahachota S, Boonyaratavej S, Kanjanavanit R, et al; TR ACS Group. Thai Registry in Acute Coronary Syndrome (TRACS)--an extension of Thai Acute Coronary Syndrome registry (TACS) group: lower in-hospital but still high mortality at one-year. J Med Assoc Thai 2012; 95:508-18.

24. Chinwong D, Patumanond J, Chinwong S, et al. Low-density lipoprotein cholesterol of less than $70 \mathrm{mg} / \mathrm{dL}$ is associated with fewer cardiovascular events in acute coronary syndrome patients: a real-life cohort in Thailand. Ther Clin Risk Manag 2015; 11:659-67.

25. Chinwong D, Patumanond J, Chinwong S, Siriwattana K, Gunaparn S, Hall JJ and Phrommintikul A. Clinical indicators for recurrent cardiovascular events in acute coronary syndrome patients treated with statins under routine practice in Thailand: an observational study. BMC Cardiovasc Disord 2015; 15:55.

26. Chin CW, Gao F, Le T, Tan R. Lipid goal attainment and prescription behavior in asian patients with acute coronary syndromes: experience from a tertiary hospital. Clin Med Insights Cardiol 2013; 7:51-7.

27. Kauffman AB, Olson KL, Youngblood ML, et al; Clinical Pharmacy Cardiac Risk Service Study Group. Attainment of low-density lipoprotein cholesterol goals in coronary artery disease. J Clin Lipidol 2010; 4:173-80.

28. Karalis DG, Subramanya RD, Hessen SE, Liu L, Victor MF. Achieving optimal lipid goals in patients with coronary artery disease. Am J Cardiol 2011; 107:886-90.

29. Chinwong D, Patumanond J, Chinwong S, et al. Statin therapy in patients with acute coronary syndrome: low-density lipoprotein cholesterol goal attainment and effect of statin potency. Ther Clin Risk Manag 2015; 11:127-36.

30. Grundy SM, Cleeman JI, Merz CN, et al; Coordinating Committee of the National Cholesterol Education Program. Implications of recent clinical trials for the National Cholesterol Education Program Adult Treatment Panel III Guidelines. J Am Coll Cardiol 2004; 44:720-32.

31. Cholesterol Treatment Trialists' (CTT) Collaborators, Mihaylova B, Emberson J, et al. The effects of lowering LDL cholesterol with statin therapy in people at low risk of vascular disease: meta-analysis of individual data from 27 randomised trials. Lancet 2012; 380:581-90.

32. Ohira T, Iso H. Cardiovascular disease epidemiology in Asia: an overview. Circ J 2013; 77:1646-52.

33. Gotoh S, Hata J, Ninomiya $T$, et al. Trends in the incidence and survival of intracerebral hemorrhage by its location in a Japanese community. Circ J 2014; 78:403-9.

34. Suwanwela NC. Stroke epidemiology in Thailand. J Stroke 2014; 16:1-7.

35. Stone NJ, Robinson JG, Lichtenstein AH, et al; American College of Cardiology/ American Heart Association Task Force on Practice Guidelines. 2013 ACC/ AHA guideline on the treatment of blood cholesterol to reduce atherosclerotic cardiovascular risk in adults: a report of the American College of Cardiology/ American Heart Association Task Force on Practice Guidelines. J Am Coll Cardiol 2014; 63:2889-934.

36. Gerstein HC, Miller ME, Byington RP, et al. Effects of intensive glucose lowering in type 2 diabetes. N Engl J Med 2008; 358:2545-59.

37. Patel A, MacMahon S, Chalmers J, et al. Intensive blood glucose control and vascular outcomes in patients with type 2 diabetes. N Engl J Med 2008; 358:2560-72.

38. American Diabetes Association. Standards of Medical Care in Diabetes-2014. Diabetes Care 2014; 37 Suppl 1:S14-80.

39. Xanthopoulou I, Davlouros P, Siahos S, etal. First-line treatment patterns and 
lipid target levels attainment in very high cardiovascular risk outpatients. Lipids Health Dis 2013; 12:170.

40. Naci $\mathrm{H}$, loannidis JP. Comparative effectiveness of exercise and drug interventions on mortality outcomes: metaepidemiological study. BMJ 2013; 347:f5577.

41. Task Force Members; Montalescot G, Sechtem U, Achenbach S, et al. 2013 ESC guidelines on the management of stable coronary artery disease: the Task Force on the management of stable coronary artery disease of the European Society of Cardiology. Eur Heart J 2013; 34:2949-3003.

42. Perk J, De Backer G, Gohlke H, et al; European Association for Cardiovascular Prevention \& Rehabilitation (EACPR); ESC Committee for Practice Guidelines CPG). European Guidelines on cardiovascular disease prevention in clinical practice (version 2012). The Fifth Joint Task Force of the European Society of
Cardiology and Other Societies on Cardiovascular Disease Prevention in Clinical Practice (constituted by representatives of nine societies and by invited experts). Eur Heart J 2012; 33:1635-701.

43. Mosca L, Benjamin EJ, Berra K, et al. Effectiveness-Based Guidelines for the Prevention of Cardiovascular Disease in Women-2011 update: a guideline from the American Heart Association. Circulation 2011; 123:1243-62.

44. Antithrombotic Trialists' (ATT) Collaboration; Baigent C, Blackwell L, Collins R, et al. Aspirin in the primary and secondary prevention of vascular disease: collaborative meta-analysis of individual participant data from randomised trials. Lancet 2009; 373:1849-60.

45. Ikeda Y, Shimada K, Teramoto T, et al. Low-dose aspirin for primary prevention of cardiovascular events in Japanese patients 60 years or older with atherosclerotic risk factors: a randomized clinical trial. JAMA 2014; 312:2510-20. 